\title{
PARTICIPACIÓN FEMENINA EN EL CRÉDITO EN UNA SOCIEDAD EN TRANSCURSO A LA MODERNIZACIÓN. CONCEPCIÓN A FINES DEL SIGLO XIX
}

Durante la época colonial las mujeres tuvieron una activa participación como proveedoras de créditos; sin embargo, con el proceso de modernización en el siglo XIX, su presencia en el ámbito financiero fue disminuyendo, contribuyendo a ello el establecimiento de los bancos. En este trabajo referido a Concepción hacia fines de ese siglo, planteamos que tal disminución se verificó en su concurrencia al mercado del crédito en función de acreedoras, pero no así en función de deudoras en la que siguieron teniendo una participación relativamente significativa, incluso aumentada. Consideramos el número de las operaciones de crédito, el estado civil de acreedoras y de deudoras, el monto de los préstamos. Intentamos construir una distribución espacial-social de las deudoras, según la ubicación de las propiedades hipotecadas. Por último, sostenemos que la menor presencia femenina en la función acreedora se vio atenuada por su participación indirecta, principalmente a través de las fianzas y de las hipotecas de propiedades pertenecientes a las esposas a las que recurrieron cónyuges endeudados ${ }^{* *}$.

Palabras clave: crédito, acreedoras, deudoras, hipotecas.

During the colonial period women were active as credit providers. However, during the process of modernization that took place in the nineteenth century their role gradually decreased, in part because of the creation of banks. In this research focusing on Concepcion, we claim that the reduced role of women in the credit system as creditors can be proven, but not that of debtors. As such, their function actually increased. Taking into account the number of credit operations, the civil status of female creditors and debtors, and the size of the loans. We have tried to establish the socio-spatial distribution of the debtors according to the location of the mortgaged properties. Finally, we maintain that women continued to play a significant, if indirected, role as creditors, mainly through the bonds and mortgages attached to properties belonging to wives who were aiding their indebted husbands.

Key words: credit, creditors, debtors, mortgages.

* Universidad de Concepción, Chile. Correo electrónico: 1mazzei@udec.cl

** Este artículo forma parte del Proyecto Fondecyt 1040367, "Reconocimiento de procesos de autonomía femenina en un contexto de subordinación. Gestión económica y la vida cotidiana de mujeres en Concepción (1840-1920)". El autor agradece la colaboración de Carlos Vivallos Espinoza en la recolección documental. 


\section{INTRODUCCIÓN}

En las sociedades tradicionales, como la sociedad chilena en la época colonial, las mujeres participaron activamente en la concesión de créditos. Como lo ha destacado Juan Guillermo Muñoz, "uno de los rubros más importantes en que la mujer tuvo gran incidencia económica fue en el mercado crediticio, pues muchas invertían parte de sus bienes en préstamos" ${ }^{1}$. María Eugenia Horvitz cita el caso de doña Francisca de la Carrera, quien entre 1778 y 1789 realizó quince operaciones de crédito $^{2}$. Por vía hereditaria, principalmente, o por otros expedientes, lograban reunir un acopio de bienes cuyos excedentes monetarios podían ser facilitados a parientes, personas que deseaban invertir, otras que necesitaban salvar contingencias económicas, o bien para satisfacer apetencias del consumo. En Concepción, las monjas Trinitarias actuaron como "verdadero banco hipotecario", en palabras de Muñoz Olave. El capital que ellas dispusieron provino de las dotes que las jóvenes aportaban al ingresar al convento, entregando como mínimo \$1.500. "Los dueños de fundo -afirma este autor- se encontraban frecuentemente dificultados en sus faenas porque, escasos de dinero, no encontraban fácilmente quién se los proporcionara. ...las trinitarias se hicieron de hecho las auxiliares de los hacendados, dándoles en préstamo los dineros provenientes de dotes de religiosas". De esta manera, según el autor que seguimos, las monjas contribuyeron al progreso de la agricultura. Muchos hacendados solicitaban en préstamo el valor de la misma dote que ellos habían pagado por el ingreso de sus hijas. Prácticamente no hubo familia de terratenientes de Concepción que no haya sido deudora de las Trinitarias, aunque no se alcanzara el valor de las dotes, puesto que gran parte de los préstamos eran por cantidades inferiores, de 100, 200 y 500 pesos $^{3}$.

Aunque no conocemos trabajos específicos sobre el crédito femenino en el siglo XIX, por lo menos para la región que nos ocupa, estimamos que durante esa centuria y con el proceso de modernización que en ella se llevó a cabo, esa función se vio muy reducida, pero siempre estuvo presente. Precisamente una de las manifestaciones más relevantes de la modernización, el establecimiento de los bancos, contribuyó a limitar el mercado crediticio para las mujeres.

Concepción hacia fines del XIX y en concordancia con la expansión económica verificada en la segunda mitad del siglo, había avanzado significativamente en el proceso modernizador. Muestras de ello son, como ejemplos ilustrativos, la extensión del ferrocarril hasta Talcahuano en el año 1876 y la presencia de varios bancos, entre ellos, el Banco Chileno Garantizador de Valores del Sur y el Banco de Concepción, ambos regionales, y las agencias de otros como el de Valparaíso y el Banco Nacional de Chile. Es en esta sociedad en transcurso a la modernización,

1 "Mujeres y vida privada en el Chile colonial", en Rafael Sagredo y Cristián Gazmuri (Directores), Historia de la vida privada en Chile. Tomo I El Chile tradicional. De la Conquista a 1840, Santiago, Aguilar Chilena de Ediciones S. A., Santiago, 2005, 120.

2 "Las operaciones de crédito y la acumulación monetaria en Chile central, 1749-1800", en Actas de la VII Jornada Nacional de Historia Regional de Chile, Santiago, Universidad de Chile, 1996, 312.

3 Véase Muñoz Olave, Reinaldo, Las Monjas Trinitarias de Concepción 1570-1822, 2a edición, Santiago, Imprenta de San José, 1926, 266-278. 
en la que nos interesa conocer y evaluar la participación femenina en el ámbito del crédito, tanto en función de acreedoras como de deudoras. Para ello hemos recogido las informaciones de mutuos hipotecarios y de cancelaciones, registradas en los volúmenes de la colección Archivo Notarial de Concepción (ANC) del Archivo Nacional, en dos momentos próximos al fin del siglo: 1885 y 1895 . Los volúmenes revisados conforman un total de doce (vols. 152 a 156 y 212 a 218), que contienen algo más de dos mil escrituras de mutuos y cancelaciones ${ }^{4}$.

\section{EL NÚMERO DE LAS OPERACIONES DE CRÉDITO}

Una primera variable que hemos considerado para evaluar la participación de la mujer en el crédito, es la que concierne al número de operaciones. No hemos puesto un límite inferior, es decir, un determinado monto a partir del cual se registran las operaciones, puesto que, cualquiera sea el monto y por bajo que fuese, implica una gestión crediticia.

\section{CUADRO 1}

DISTRIBUCIÓN DE LOS ACREEDORES SEGÚN NÚMERO

DE OPERACIONES DE CRÉDITO, 1885 Y1895

\begin{tabular}{|c|c|c|c|c|}
\hline \multirow[b]{2}{*}{ Categorías } & \multicolumn{2}{|c|}{1885} & \multicolumn{2}{|c|}{1895} \\
\hline & & $\%$ & & $\%$ \\
\hline Hombres & 206 & 63,2 & 396 & 61,6 \\
\hline Mujeres & 44 & 13,5 & 73 & 11,3 \\
\hline Bancos & 55 & 16,9 & 137 & 21,3 \\
\hline Sociedades & 12 & 3,9 & 30 & 4,7 \\
\hline Sucesiones & 7 & 2,2 & 6 & 0,9 \\
\hline Instituciones & 3 & 0,3 & 1 & 0,2 \\
\hline TOTAL & 327 & 100,0 & 643 & 100,0 \\
\hline
\end{tabular}

Los datos del cuadro precedente muestran que las mujeres realizaron 44 préstamos durante el año 1885, que representaron un valor relativo de un 13,5\%, bastante inferior al de los acreedores hombres que concitaron el mayor número de operaciones (en términos relativos más del 60\%); en cambio las cifras de las mujeres no se apartaron mucho de las correspondientes a los bancos, aunque debe tenerse presente que hay escrituras de aperturas de cuentas corrientes y de cesiones de créditos que incrementaban la participación de estas instituciones; además los créditos de

4 Todas las escrituras que indicamos en el texto corresponden a estos volúmenes, por lo que, para no cansar excesivamente al lector, nos ahorramos las referencias de pie de página, salvo en las citas textuales y en algún volumen que no corresponde a los señalados. 
los bancos solían ser por cantidades más altas ${ }^{5}$. En las sociedades comerciales o compañías, algunas veces aparece como acreedor el socio principal (por ejemplo, José Miguel Galán en Galán Hermanos y Plácido Carmona en Carmona y Cía.); de este modo se ve aumentado el número de hombres acreedores en desmedro de las compañías. En todo caso, en lo que atañe a las mujeres, su participación relativa debió haber estado por sobre el $10 \%$, porcentaje que no es desestimable. En un trabajo anterior, basado en una muestra de 110 casos, correspondientes al año 1880 , el porcentaje de las mujeres acreedoras alcanzó a un $17 \%{ }^{6}$. Una muestra más bien reducida no es comparable con un recuento exhaustivo como el que ahora realizamos; sin embargo, la diferencia que se advierte puede ser indicio de un descenso de la participación relativa de las mujeres como acreedoras. En cuanto a los tres préstamos hechos por instituciones, ellos corresponden al Liceo, Seminario y Hospital de Hombres de Concepción.

Al confrontar el número de las operaciones de crédito efectuadas por acreedores entre los años 1885 y 1895, vemos que ellas aumentan considerablemente: de 327 en el primer año indicado suben a 643 en el segundo, lo cual implica un aumento cercano a una duplicación $(96,6 \%)$. En lo referente al número absoluto de créditos otorgados por mujeres, crece de 44 a 73; hubo, pues, 29 operaciones más. No obstante, este incremento en el número absoluto no es corroborado en términos relativos, ya que el porcentaje alusivo a mujeres desciende de un 13,5\% a un $11,3 \%$, es decir, una disminución de algo más de dos puntos porcentuales. El porcentaje de aumento de las mujeres acreedoras es bastante inferior al de los varones $(92 \%)$ y a los de los bancos y sociedades mercantiles (150\% en cada una de estas categorías). De manera que la mujer participó en forma limitada en la expansión crediticia de fines del XIX, corroborándose la tendencia decreciente femenina en la función acreedora.

CUADRO 2

DISTRIBUCIÓN DE LOS DEUDORES

SEGÚN NÚMERO DE OPERACIONES DE CRÉDITO, 1885 Y 1895

\begin{tabular}{lrrrrr}
\hline & \multicolumn{2}{c}{1885} & & \multicolumn{2}{c}{1895} \\
\cline { 2 - 3 } \cline { 5 - 6 } Categorías & 298 & 81,4 & & 502 & $\%$ \\
\hline Hombres & 63 & 17,2 & & 153 & 74,6 \\
Mujeres & 1 & 0,3 & & 12 & 22,8 \\
Sociedades & 4 & 1,1 & 3 & 0,4 \\
Sucesiones & & & 3 & 0,4 \\
Instituciones & 366 & 100,0 & 673 & 100,0 \\
TOTAL & & & &
\end{tabular}

\footnotetext{
5 Váese infra 6. Montos de los créditos.

6 Mazzei de Grazia, Leonardo, "El crédito en el tránsito de una sociedad tradicional a una sociedad moderna. Concepción hacia 1880”, en Revista de Historia, Universidad de Concepción, vol. 15, $2005,134$.
} 
El número de las deudas totales subió de 366 en 1885 a 673 diez años después, deduciéndose que el ritmo de incremento de las acreencias totales es superior al de las deudas ${ }^{7}$. Sin embargo, en el caso de las mujeres deudoras, de 63 préstamos solicitados en 1885 pasan a 153 en 1895; son noventa operaciones más, equivalentes a cerca de un $150 \%$. En contraposición a lo que ocurre en las acreedoras, el alza en cifras absolutas de las deudoras, es ratificada por el incremento relativo que las empina por sobre un $20 \%$ del total de deudores. Las mujeres, pues, se endeudan en mayor volumen y proporción en comparación con su gestión de acreedoras. Esta situación difiere de lo que era habitual en la sociedad tradicional, en la que el valor de los préstamos otorgados por mujeres era mayor que el valor de sus deudas. Todavía en la muestra que hicimos para el año 1880 , las acreencias femeninas $(17,1 \%)$ prevalecían por sobre las deudas $(15,2 \%)$, aunque si bien ligeramente. De modo que con el proceso de modernización la mujer perdió importancia concurriendo al mercado crediticio como acreedora; pero no ocurrió lo mismo en función de deudora, en la cual su participación aumentó.

\section{ACREEDORAS Y DEUdORAS SEGÚN ESTADO CIVIL}

La población total de la provincia de Concepción durante el período intercensal 1885-1895 aumentó muy poco: de 182.459 habitantes pasó a 188.190 , lo que equivale a una tasa aproximada de solo $0,3 \%$ anual. Dentro de este bajo incremento, el ritmo de aumento de las mujeres fue superior al de los varones. Estos subieron de 91.382 a 91.998 (0,1\% anual); es decir, la población masculina se mantuvo prácticamente estable. Las mujeres, en cambio, pasaron de 91.077 a 96.192 (0,5\% anual). El mayor incremento del número de mujeres pudo haber favorecido una participación más alta de ellas en el mercado del crédito. Pero lo que interesa es conocer si este incremento femenino se verificó a partir de las edades en que podían contraer nupcias, para hacer comparables las diversas categorías del estado civil. Desgraciadamente los respectivos censos de población, en las tabulaciones del estado civil consideran a toda la población sin fijar un límite inferior de edad, por lo que es necesario restar de la distribución etaria femenina a aquellas que estaban bajo un límite inferior de edad, que en nuestro caso lo hemos fijado en 15 años. La distribución resultante se presenta en el cuadro siguiente.

7 Mientras el aumento de las operaciones de acreencia totales fue equivalente a un 96,6\%, el de las operaciones de deuda totales fue de un $83,8 \%$. 
CUADRO 3

COMPOSICIÓN SEGÚN ESTADO CIVIL DE LA POBLACIÓN FEMENINA DE 15 AÑOS Y MÁS DE LA PROVINCIA DE CONCEPCIÓN, CENSOS DE 1885 Y 1895

\begin{tabular}{lrrrrr}
\hline & \multicolumn{2}{c}{1885} & & \multicolumn{2}{c}{1895} \\
\cline { 2 - 3 } \cline { 5 - 6 } Categorías & \multicolumn{1}{c}{$\mathrm{N}^{\circ}$} & $\%$ & & $\mathrm{~N}^{\circ}$ & $\%$ \\
\hline Solteras & 31.690 & 52,4 & & 31.915 & 50,8 \\
Casadas & 22.536 & 37,3 & & 23.219 & 36,9 \\
Viudas & 6.211 & 10,3 & & 7.748 & 12,3 \\
Divorciadas & 29 & 0,0 & & 20 & 0,0 \\
TOTAL & 60.466 & 100,0 & & 62.902 & 100,0 \\
\hline
\end{tabular}

Se infiere de los datos del cuadro que el ritmo de crecimiento de la población femenina de 15 años y más $(0,4 \%$ anual) es inferior al porcentaje de incremento del total de mujeres $(0,5 \%$ anual), por lo que el aumento femenino se verificó en las edades infantil y juvenil. Solo las viudas aumentaron su valor numérico y su peso relativo, lo que pudo haber influido en alguna medida en el incremento de su participación en las gestiones de crédito. Pero, en definitiva, el mayor crecimiento de la población femenina no parece haber sido un factor importante en la presencia de las mujeres en los préstamos. Ello obedeció a otras causas, como fueron las herencias recibidas de sus esposos fallecidos en el caso de las viudas, que quedaban con parte substancial de ellas y, cuando no había descendencia, con todos los bienes que el difunto esposo dejaba (descontados los legados, obras pías, ofrendas de misas y otros desgloses); asimismo las solteras recibían herencias de sus padres, valores que podían invertirse en mutuos hipotecarios. Ambas disponían de libertad para otorgar $\mathrm{u}$ obtener créditos o para emprender otras gestiones económicas. De ahí que las acreedoras fueran casi en su totalidad mujeres viudas y solteras. En los datos del cuadro 4 se constata que en 1885 las viudas superaban el 55\% de las operaciones de acreencia, mientras que en 1895 las solteras sobrepasaron levemente a las viudas, repartiéndose casi por igual el número de operaciones de las acreedoras.

CUADRO 4

DISTRIBUCIÓN DE LAS ACREEDORAS SEGÚN ESTADO CIVIL, 1885 Y 1895

\begin{tabular}{lrrrrr}
\hline & \multicolumn{2}{c}{1885} & & \multicolumn{2}{c}{1895} \\
\cline { 2 - 3 } \cline { 5 - 6 } Categorías & $\mathrm{N}^{\circ}$ & $\%$ & & $\mathrm{~N}^{\circ}$ & $\%$ \\
\hline Viudas & 25 & 56,8 & & 34 & 46,6 \\
Solteras & 18 & 41,0 & & 36 & 49,3 \\
Casadas & 1 & 2,2 & & 3 & 4,1 \\
TOTAL & 44 & 100,0 & & 73 & 100,0 \\
\hline
\end{tabular}


La participación de la mujer casada como acreedora fue insignificante. Ello se explica por su menor libertad para actuar en la vida pública, debiendo contar con el permiso del marido para conceder u obtener créditos, para vender o comprar propiedades u otros bienes o para ejercer oficios ${ }^{8}$. Lo más frecuente era que no subscribieran los contratos directamente, sino que fueran representadas por los esposos. Ilustrativo de las autorizaciones maritales es el caso de Domitila Guerra, a quien su marido le otorgó permiso para que se dedicara "al comercio de frutos del país y zapatería a que se ha conectado haciendo su profesión habitual desde hace algunos años atrás""; por su parte, Eugenia Vergara de Morales fue autorizada por su cónyuge "para que ejerza la profesión de comerciante... <y $>$.. para que venda $\mathrm{o}$ hipoteque los bienes pertenecientes a ella" $"$.

\section{CUADRO 5}

DISTRIBUCIÓN DE LAS DEUDORAS SEGÚN ESTADO CIVIL, 1885 Y 1895

\begin{tabular}{lcccrr}
\hline \multirow{2}{*}{ Categorías } & \multicolumn{2}{c}{1885} & & & \multicolumn{2}{c}{1895} \\
\cline { 2 - 3 } \cline { 5 - 6 } & $\mathrm{N}^{\circ}$ & $\%$ & & $\mathrm{~N}^{\circ}$ & $\%$ \\
\hline Viudas & 32 & 50,8 & & 69 & 45,1 \\
Solteras & 20 & 31,7 & & 63 & 41,2 \\
Casadas & 11 & 17,5 & & 21 & 13,7 \\
TOTAL & 63 & 100,0 & & 153 & 100,0 \\
\hline
\end{tabular}

En las deudoras, las viudas mantuvieron su supremacía durante todo el período, pero su peso relativo descendió de $50,8 \%$ a $45,1 \%$, en favor de un mayor incremento numérico y porcentual de las solteras. En las casadas se observa que, sin llegar a acercarse a viudas y solteras, actuaron mucho más como deudoras que como acreedoras, debidamente representadas por sus esposos o contando con la autorización de ellos. Algunos ejemplos: María Matilde Figueroa fue representada por su marido para recibir un préstamo de poco más de 1.000 pesos de su propio hermano; Leonarda Barra, por intermedio también del esposo, obtuvo un préstamo de 300 pesos, con hipoteca de un sitio y casa de propiedad de la mujer, en calle Las Heras en la periferia de la ciudad de Concepción. Es posible advertir en algunas escrituras, la presencia de mujeres que si bien no eran casadas, estaban unidas por largos años de convivencia, lo que se deduce de las hipotecas de propiedades tenidas en común, sin que mediara ninguna especificación de unión matrimonial o de parentesco. Así, Dionisia Salgado y Ángel Saavedra consiguieron menos de 100 pesos, en un préstamo que fue respaldado con la hipoteca de un rancho pajizo en

8 Las Leyes de Indias señalaban específicamente la incapacidad de la mujer casada para celebrar contratos, salvo que tuvieran permiso expreso del marido. Véase Horvitz, art. cit., 307.

9 ANC, vol. 154, fs. 117-118.

10 Ibidem, vol. 212, fs. 182-183v. 
calle Maipú de Concepción. Dolores Prieto y Pedro Alcántara obtuvieron 200 pesos con hipoteca de sitio y casa en la misma calle. En muy pocas oportunidades se especifica la condición de soltera de la conviviente; así lo declaró Micaela Villagrán, quien junto a Juan de Dios Amaya hipotecó un terreno de seis cuadras en el área agrícola de Hualqui, para conseguir 200 pesos.

\section{LAS ACREEDORAS}

Las mujeres que concedían créditos eran prestamistas ocasionales. Hubo pocas que hicieron varias operaciones de préstamo en un mismo año. Una de ellas fue doña Cruz Godoy viuda de Concha, quien en 1885 registró cinco gestiones crediticias en montos variables entre 3.000 pesos y 200 pesos. Era doña Cruz natural del departamento del Laja y vecina de la ciudad de Concepción; en su testamento declaró que le adeudaban varias cantidades y que ella no debía suma alguna; era propietaria de cinco fundos: Quilacoya, La Higuerilla y Toquihua en el departamento de Rere; Santa Cruz en el de Puchacay y San Carlos en el departamento del Laja, que había adquirido por herencias o durante la sociedad conyugal. Sus legados favorecieron a parientes cercanos, en sumas de hasta 5.000 pesos y en propiedades; a sirvientes en reconocimiento por sus servicios; al Seminario Conciliar de Concepción al que dejó 7.000 pesos a cambio de misas por el bien de su alma, la de su marido, las de sus padres y la de una tía que le había dado en herencia el fundo Quilacoya. En el remanente de sus bienes, a falta de hijos, instituyó como heredera universal a su sobrina doña Rosario Brito, "que me ha servido y cuidado hasta el presente"11. La sobrina no siguió la misma senda de doña Cruz y solo se registra de ella una acreencia que, en su calidad de casada, contó con la respectiva autorización marital; el mismo cónyuge se encargó de cancelar varios préstamos que quedaron a favor de doña Cruz a su fallecimiento. A diferencia de las mujeres hubo numerosos hombres que hicieron del préstamo a interés su gestión principal o una de sus gestiones principales. Entre ellos, José María Avello, Reinaldo Behrens, José María Castro, José Miguel Galán, Juan Bautista Melo, Lorenzo Mercado, Francisco Solano González y el notario Narciso Segundo Silva.

En estas acreedoras ocasionales encontramos a mujeres de diferentes condiciones: pertenecientes a la elite latifundista local, medianas propietarias agrícolas, rentistas, comerciantes, también algunas extranjeras. Prestaban a terratenientes (doña Isabel Unzueta, soltera, facilitó a Luis Barros Méndez 1.800 pesos con un bajo interés del 7\% anual, quizás por estar emparentados; ambos pertenecían a reconocidas familias de propietarios agrícolas, aunque el deudor no hipotecó esta vez alguna propiedad rural, sino casa y sitio en calle San Martín en el área central de la ciudad). Hubo préstamos a pequeños y medianos agricultores (Carolina Silva Pasquel, soltera, otorgó 500 pesos, al interés del 1\% mensual, a José del Carmen Bello quien respaldó la transacción gravando un retazo de terreno con lo edificado

11 Testamento de doña Cruz Godoy viuda de Concha, ibidem, vol. 166, fs. 518-521. 
y plantado de nueve cuadras aproximadas de extensión, ubicado en la zona rural de Hualqui; Tránsito Oliva Fernández, señorita según se especifica en la escritura, otorgó a Mateo Leiva, 3.000 pesos, al mismo interés antes indicado, con hipoteca de cuarenta cuadras en el departamento de Rere). A comerciantes (Carmen Azócar viuda de Boggiano concedió 1.500 pesos a José Miguel Galán, quien era su apoderado). A pequeños comerciantes y artesanos; aunque en escasas ocasiones en las escrituras de cancelaciones y mutuos se especifica la ocupación u oficio, deducimos esta condición en forma aproximada por la ubicación en barrios periféricos de la ciudad de las propiedades hipotecadas por solicitantes de préstamos. Abel Contreras se endeudó por 2.500 pesos, al interés del 10\% anual, con doña Cruz Godoy viuda de Concha, a quien ya conocemos, hipotecando para el efecto sitio y casa en la calle de Rozas, barrio de Polanco; Fernando Gaete contrajo una deuda de 400 pesos con doña Rosario Palma, soltera, hipotecando sitio y casa en calle Cruz. Registramos un crédito hecho a un profesional: doña Maclovia Rossel otorgó en préstamo 5.000 pesos al médico Juan Bautista Henríquez, con cuyo valor este compró a la misma acreedora una casa en el área central de la ciudad; al médico parece haberle ido bien en el ejercicio de su profesión, porque pudo cumplir con el pago de la deuda en el plazo estipulado de tres años, a diferencia de lo que solía ocurrir con los pagos que sobrepasaban, en ocasiones holgadamente, los plazos. Figuran también entre los prestatarios algunos extranjeros de radicación reciente (doña Domitila Rozas viuda de Urrutia concedió a Teodoro Herbstaedt 200 pesos, a pagarse en cómodas mensualidades de 10 pesos cada una, sin intereses y sin hipotecas; Otto Welkner, alemán, contrajo un mutuo con Francisca Reckmann, señorita, de la misma nacionalidad, por 3.500 pesos, al interés de solo $71 / 2 \%$ anual, con hipoteca de un sitio en la avenida Agua de las Niñas ${ }^{12}$,en la salida suroriente de la ciudad).

Varios préstamos fueron otorgados por las acreedoras a personas que se instalaban en la zona fronteriza de la Araucanía. Citamos algunos casos: Feliciana Eberling, soltera, facilitó a Juan Modini 400 pesos, con interés del $8 \%$ anual, hipotecando el deudor sitio y casa en el nuevo pueblo de Nueva Imperial, en el territorio de colonización de Angol; Pabla Ruiz, soltera, a Elvio Moreira, 4.000 pesos, al interés del $11 \%$ anual, con hipoteca de la acción y derecho que correspondían al deudor en la hijuela o fundo Pile, en el departamento de Mulchén; limitando esos terrenos al norte con el estero Pile y el río Biobío, al oriente con la cordillera de los Andes y al sur con el río Bureo; Moreira, además, hipotecó una propiedad vecina perteneciente a su esposa. Hemos sostenido en otro trabajo, que la elite terrateniente de Concepción fue reacia a extender sus gestiones al área fronteriza y que la captación del trigo de esa zona fue obra de empresarios extrarregionales y de firmas extranjeras ${ }^{13}$. Sin embar-

12 La avenida o barrio Agua de las Niñas, actualmente avenida Pedro de Valdivia, que comunica a Concepción con la localidad de Chiguayante, fue poblada por inmigrantes europeos, principalmente británicos, alemanes y franceses.

13 Mazzei de Grazia, Leonardo, "La economía de Concepción en el cambio de siglo (XIX-XX). Avance y (des)proyección", en Revista de Estudios Trasandinos, año IV, No 4, Revista de la Asociación Argentina Chileno de Estudios Históricos e Integración Cultural, Santiago, 2000. 
go, a través de estos créditos femeninos otorgados en Concepción podemos advertir una forma de contribución al proceso de radicación en la Araucanía. Se trata, por lo general, de préstamos de baja y mediana cuantía (aunque se registran algunos por 4.000 pesos y aun algo más), a gente que veía la posibilidad de realizar una nueva gestión emprendedora. En los hombres acreedores este tipo de préstamo fue mucho más frecuente y también los bancos en ocasiones prestaban a instalados en aquellos territorios. De manera que se trataba de un proceso generalizado. Usualmente los bancos no concedieron muchos créditos a las mujeres; cualquiera fuese el tipo de contrato, fueron muy escasas las que, por ejemplo, consiguieron abrir cuenta corriente en una institución financiera. Entre las radicadas en la frontera hubo algunas que obtuvieron mutuos bancarios; así, a María Mercedes Ugalde, domiciliada en la población de Temuco, el Banco Chileno Garantizador de Valores del Sur de Concepción, entregó 4.305 pesos, a pagarse en veinte años, al interés del $8 \%$ anual. El caso es reflejo también de la participación femenina en el ámbito productivo y/o mercantil en el desarrollo de la ocupación de la Araucanía.

Las acreedoras destinaron la mayor parte de sus mutuos a otras mujeres y a parientes, expresándose así una solidaridad femenina y una solidaridad familiar. En el año 1895 un tercio de los préstamos de las acreedoras fueron proporcionados a otras mujeres, haciéndolo a veces sin interés o bien con intereses muy bajos o sin mediar hipotecas. Ello es demostrativo de la presencia de la solidaridad femenina, tanto en la elite local como en sectores modestos. Michelina Gana viuda de Gana otorgó un mutuo por 200 pesos a María Berndt viuda de Michaelis, con interés de $8 \%$ anual y sin hipotecas. Petrona Saavedra, viuda, domiciliada en Hualqui, compró a Juana Asquén, soltera, sitio y casa en calle Arturo Prat, periferia de Concepción, en 400 pesos que pagó al contado; al mismo tiempo la compradora recibió un mutuo de la vendedora por 300 pesos sin intereses, pero con hipoteca de la propiedad comprada. Agreguemos que en los días de esta transacción la deudora reconoció como hijas naturales a Carmen y Florentina, habidas cuando estaba soltera con Rafael Vega, asimismo soltero; lo hizo para que "legalmente entren a gozar los derechos que les corresponden en mérito de este reconocimiento"14. Más allá de esta confesión íntima de doña Petrona, creemos que el cambio de su domicilio de Hualqui a Concepción es manifestación del proceso migratorio campo-ciudad, al que nos referiremos más adelante.

Elvira Díaz viuda de Peña prestó a su hermana Felicinda Díaz, soltera, 1.300 pesos, con un bajo interés de $6 \%$ anual, pero sí con hipoteca de dos retazos de terreno en el barrio Andalién en la salida del camino de Concepción a Penco, lo cual es indicativo de que la solidaridad femenina admitía ciertos resguardos. Aun más, tal solidaridad tendió a decrecer, siendo numerosos los préstamos de mujeres a otras mujeres y también a hombres, en los que hubo exigencias de altos intereses y de hipotecas. Doña Jesús Pacheco viuda de Ramos, por ejemplo, concedió en mutuo a Andrés Medina 250 pesos, a pagarse en un año, con un subido interés de $1 \frac{1}{2} \%$ mensual (equivalente a $18 \%$ anual), y con hipoteca de casa y sitio en calle

14 ANC, vol. 153, fs. 404. 
Las Heras en la periferia de Concepción. Los mutuos otorgados en tales condiciones pueden ser síntoma de que la solidaridad de la sociedad tradicional iba cediendo ante el monetarismo capitalista que fue envolviendo también a las mujeres. Es decir, ellas se hicieron partícipes del proceso de modernización económica, aunque esta tendía a relegarlas en su función de acreedoras.

En lo referente a los créditos destinados a parientes, ya hemos aludido a uno de ellos en líneas anteriores. Otro es el de doña María Jesús Rodríguez viuda de Ibieta a su hijo el presbítero Juan de Dios Ibieta, por 3.000 pesos, a pagarse en un año, con interés del $10 \%$ anual y dando el deudor en garantía una escritura de mutuo a su favor por la suma de 10.000 pesos, con hipoteca de propiedades agrícolas en el departamento de Coelemu. El mutuo femenino por más alto valor en 1885 se realizó entre parientes; fue el que concedió doña Manuela Murillo viuda de Mahuzier a cuatro de sus hijos: Juan Germán, Juan Enrique, Juan Carlos y Juan Julio ${ }^{15}$. El mutuo en cuestión se hizo por el valor de 50.000 pesos, suma que los referidos hijos quedaron debiendo a la madre viuda por la compra de sus derechos y acciones en los fundos Quillay, La Palma, Canifrú, San Miguel, Dehunihue, Barra, Pangal, curtiembre de la Mochita, quinta de la Mochita y otros bienes; se fijó un interés de 3\% anual, un plazo de diez años e hipotecas sobre el fundo Quillay de 250 cuadras, el establecimiento de curtiembre de la Mochita (el más moderno en su ramo en Concepción), la quinta de la Mochita de 33 cuadras de extensión, "y además se obligan a darle la comida y el alojamiento en la casa habitación mientras viva la señora Murillo y se pague el capital"16. Al finalizar el plazo, el préstamo se renovó por el mismo valor nominal de 50.000 pesos, con una leve alza del interés a un $4 \%$ anual ${ }^{17}$. Los cuatro hermanos que se hicieron cargo de los negocios familiares, quedaron debiendo además a otros hermanos y hermanas, aunque en cantidades menores que la obtenida de la madre viuda. Así, adeudaban a Adela Mahuzier viuda de Arnouil 15.000 pesos, de los cuales 10.000 pesos eran por concepto de mutuo, al interés del $10 \%$ anual, y 5.000 pesos por compra de sus derechos hereditarios, al interés del $3 \%$ anual.

15 El padre fallecido era Jean Gustave Mahuzier, francés. Tuvo numerosas propiedades agrícolas en la zona de Yumbel, pero destacó más en la industria con el establecimiento de curtiembre de la Mochita. No figura en el empadronamiento de franceses en Chile efectuado en 1886, que reproducen Lavalle y Agard-Lavalle, por estar ya fallecido, pero sí aparecen sus hijos. Véase Lavalle, Bernard y Francine Agard-Lavalle, "Los franceses en el sur chileno según el empadronamiento de 1886", Apéndice, 219, en Jorge Pinto Rodríguez (Editor), Modernización, inmigración y mundo indígena. Chile y la Araucanía en el siglo XIX, Temuco, Ediciones Universidad de la Frontera, 1998.

16 ANC, vol. 154, fs. 459-460v.

17 Especificamos que se trata de valor nominal porque entre 1885 y 1895 descendió notablemente el cambio monetario: de 26 peniques por peso a 17 peniques por peso. Sin embargo, la distribución porcentual del valor de los préstamos concedidos por las acreedoras no varió substancialmente. Así, considerando el número de operaciones, los préstamos inferiores a 500 pesos representaron un 30,2\% en 1885 y un $29,5 \%$ en 1895 ; los de 500 pesos hasta 2.500 pesos, $41,9 \%$ y $44,1 \%$, respectivamente; y los de 3.000 pesos y más, $27,9 \%$ y $26,4 \%$, respectivamente. 


\section{LAS DEUDORAS}

Al igual que en el caso de las acreedoras, en las deudoras encontramos a mujeres de diferentes condiciones. Hay mujeres de la elite local; residentes en áreas periféricas de la ciudad de Concepción; domiciliadas en otras localidades de la provincia; mujeres de áreas rurales.

¿Para qué ellas solicitaban o pagaban mutuos? Las informaciones que proporcionan las escrituras de mutuos y cancelaciones no dan a conocer el motivo de los préstamos, salvo en pocos casos. Uno de ellos es el de Rita García viuda de Jara y Clementina Santibáñez, soltera, vecinas de Hualqui, quienes pidieron a Francisco Solano González, prestamista habitual en la región, 500 pesos, con interés del $10 \%$ anual y por un año, obligándose "a responder con el negocio que van a poner con ese dinero"18; aunque no se especifica de qué negocio se trata, lo más probable es que fuera una tienda de comercio en el pueblo de que eran vecinas. Asimismo aparece explicitada la destinación de un crédito por 300 pesos conseguido por Adelaida Quijada, soltera, "para la construcción del edificio que tiene en su casa de calle Paicaví de esta ciudad"19. En las pocas escrituras que indican ocupación u oficio se puede deducir que el préstamo solicitado era para invertirlo en sus gestiones: Clorinda San Martín, casada, comerciante, con el permiso de su marido, recibió de Lorenzo Mercado, también prestamista frecuente, 500 pesos al interés del $1 \frac{1}{2} \%$ mensual y con hipoteca de sitio y casa en calle Paicaví; Emilia Quezada, igualmente comerciante y casada debidamente autorizada por su esposo, subscribió un mutuo por 700 pesos, al mismo interés del $1^{1 /}$ ${ }_{2} \%$ mensual, con hipoteca de casa y sitio en el pueblo de Hualqui; en este caso no se invirtió en negociaciones propias del giro, al menos la mayor parte de la suma conseguida, ya que 500 pesos fueron destinados a la compra de un sitio con lo edificado y plantado en el mismo pueblo.

En las cancelaciones, que muchas veces se hacían bastante excedido el plazo estipulado, hay varios casos de pagos finiquitados para alzar hipotecas y vender la propiedad o los derechos a propiedades que estaban bajo gravamen. Así, Clorinda Torres viuda de Silva pagó un préstamo de 200 pesos, dejando libre de hipoteca la acción y derecho que le correspondían en un sitio y casa en calle Las Heras en Concepción, pudiendo así vender esa acción y derecho, lo que hizo junto con su hija Elcira y el esposo de esta, que también tenían derechos sobre la propiedad hipotecada; la venta se hizo por 850 pesos al contado. Situación semejante fue la de Mercedes Cordero viuda de Pregnan, quien se endeudó con el prestamista Francisco Solano González por 800 pesos, hipotecando sitio y casa en calle Ignacio Serrano de la ciudad; al pagar vendió la propiedad libre de hipoteca en 2.000 pesos. Se puede advertir que luego de la venta quedaba un saldo monetario a favor de las deudoras-vendedoras.

\footnotetext{
18 ANC, vol. 212, fs. 384v-385

19 Ibidem, vol. 214 , fs. $156 \mathrm{v}$.
} 
En números absolutos las operaciones de las deudoras por montos inferiores a 500 pesos, subieron de 29 en 1885 a 62 en 1895. Pensamos que en este incremento influyó el encarecimiento del costo de la vida, que habría motivado a muchas mujeres a endeudarse por razones de subsistencia ${ }^{20}$.

\section{BIENES HIPOTECADOS Y DISTRIBUCIÓN ESPACIAL-SOCIAL DE LAS DEUDORAS}

Los bienes que se hipotecaban para percibir mutuos eran inmuebles: propiedades fueran rurales o urbanas. En contadas ocasiones se gravaba otro tipo de pertenencias, acciones de bancos u otros bienes. Por ejemplo, en un crédito solicitado por Juan Cohen a Almena S. Rabson, señorita, por 4.000 pesos, sin intereses y a pagarse en dividendos de 100 pesos cada uno, el deudor constituyó prenda a favor de la acreedora sobre una máquina molinera; a la vez le hizo donación mortis causa de la máquina, cuyo valor se estimaba en la misma suma del préstamo; por su parte, la señorita Rabson hizo también donación mortis causa al deudor del monto del empréstito. Sin duda que allí mediaba una relación de tipo afectivo. Pero como afirmamos, las hipotecas gravaban fundamentalmente a propiedades, siendo excepcional el caso citado.

Hemos realizado una distribución espacial de las deudoras, considerando la ubicación de las propiedades hipotecadas. Esta ubicación espacial tiene una correlación social, puesto que adoptamos como supuesto que aquellas damas que gravaban propiedades en el área central de Concepción pertenecían a la elite local, mientras que las que hipotecaban propiedades en barrios periféricos, correspondían a los sectores medios y populares. Es cierto que mujeres de la elite eran dueñas de propiedades en sectores de la periferia, pero no son tantos los casos como para que aparezca distorsionada la distribución espacial-social que intentamos. En la figura 1 presentamos un plano de la ciudad de Concepción, en que hemos cerrado en un rectángulo su área central, delimitada por calle Angol por el sur; Tucapel por el norte; Freire por el poniente y calle Chacabuco por el oriente.

20 Entre los años considerados subió el precio de productos tales como las arvejas de 3 pesos los cien kilos a 6 pesos; los frijoles, de 5 pesos los cien kilos a 11 pesos; los garbanzos, de 8 pesos los cien kilos a 20 pesos; las lentejas de 5 pesos los cien kilos a 8 pesos (informaciones recogidas del diario El Sur de Concepción). 
FIGURA 1

PLANO DE LA CIUDAD DE CONCEPCIÓN CORRESPONDIENTE AL AÑO 1892

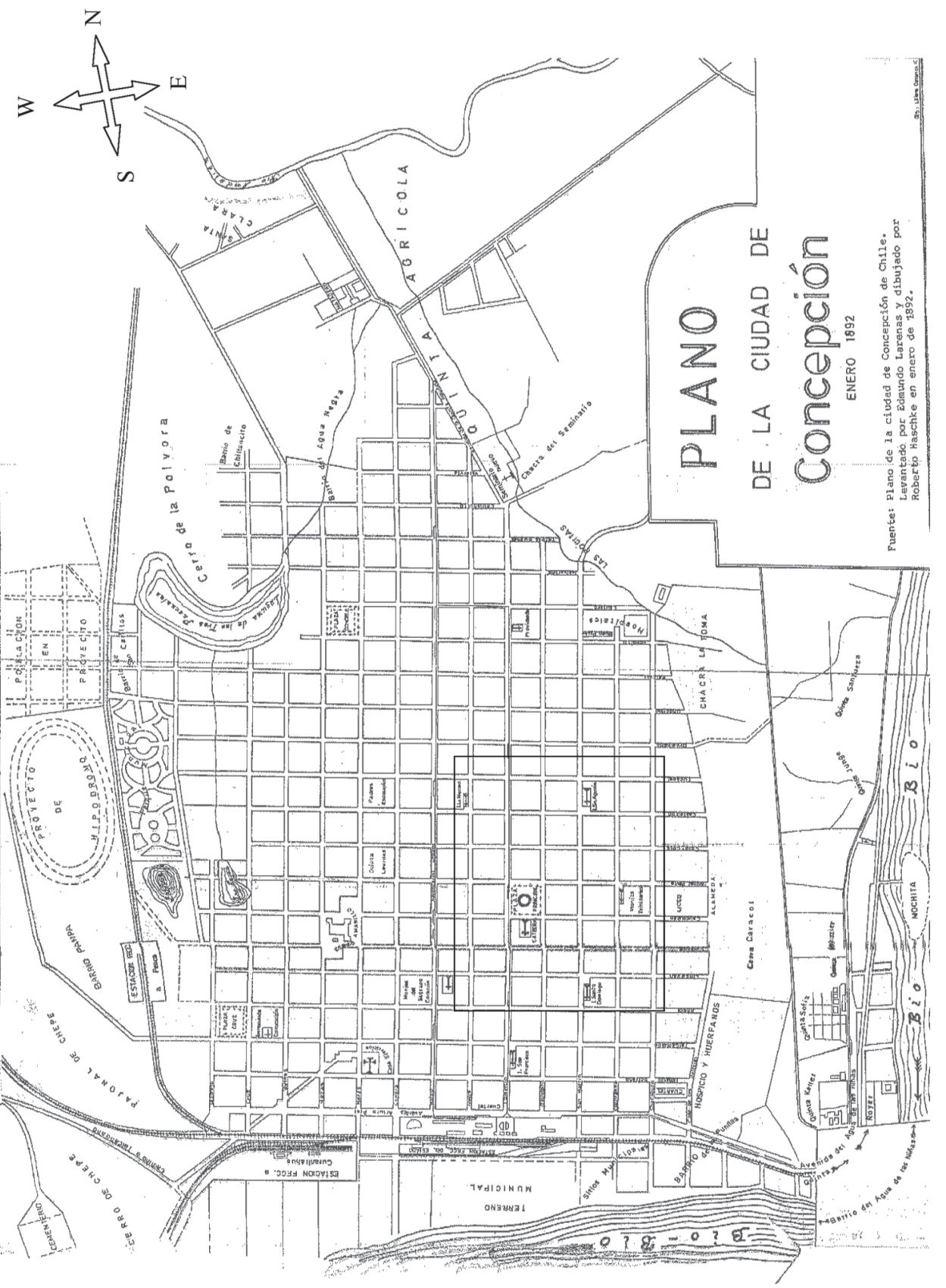




\section{FIGURA 2}

MAPA DE LA REGIÓN DE CONCEPCIÓN

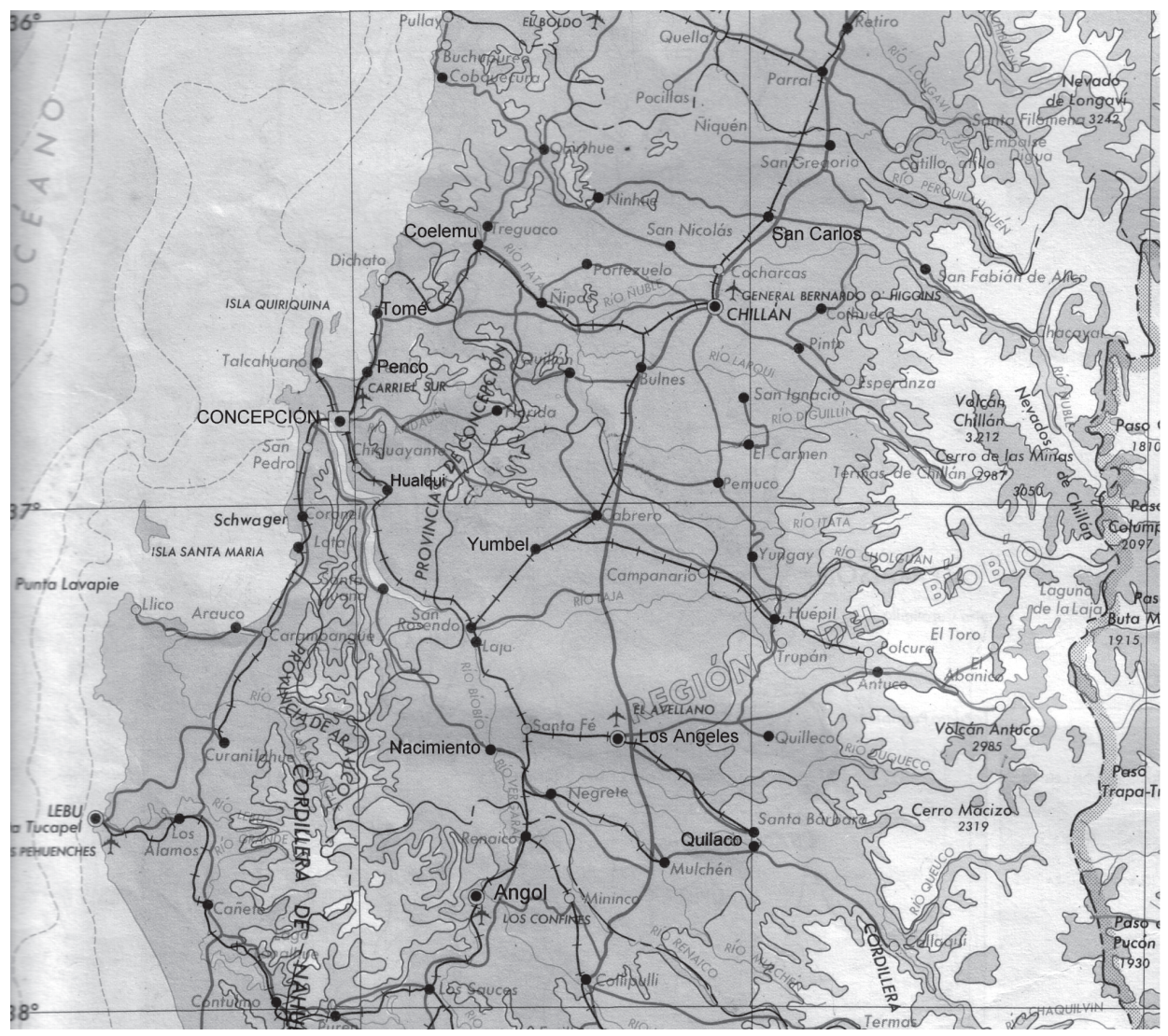

\section{CUADRO 6}

DISTRIBUCIÓN ESPACIAL DE LAS DEUDORAS SEGÚN PROPIEDADES HIPOTECADAS, 1885 Y 1895

\begin{tabular}{|c|c|c|c|c|}
\hline \multirow[b]{2}{*}{ Ubicación } & \multicolumn{2}{|c|}{1885} & \multicolumn{2}{|c|}{1895} \\
\hline & $\mathrm{N}^{\circ}$ & $\%$ & $\mathrm{~N}^{\circ}$ & $\%$ \\
\hline Área central de Concepción & 11 & 18,7 & 36 & 27,3 \\
\hline Áreas periféricas & 22 & 37,3 & 60 & 45,4 \\
\hline Áreas rurales & 19 & 32,2 & 24 & 18,2 \\
\hline Otras ciudades de la región & 7 & 11,8 & 8 & 6,1 \\
\hline Localidades de fuera de la región & - & - & 4 & 3,0 \\
\hline TOTAL & 59 & 100,0 & 132 & 100,0 \\
\hline
\end{tabular}


Tanto en el año 1885 como en 1895 el mayor número de deudoras es el de las domiciliadas en barrios periféricos de la ciudad, las que además entre un año y otro suben su peso relativo hasta aproximarse a la mitad de los créditos obtenidos. Esta situación se relaciona con el proceso migratorio campo-ciudad. Hemos señalado en páginas anteriores que la población total de la provincia de Concepción aumentó muy poco en el período intercensal 1885-1895. Sin embargo, la distribución interna de la población de la provincia en áreas urbanas y rurales varió notablemente; mientras en el primer año indicado la población rural sumó 115.841 personas, un $63,5 \%$, la urbana registró 66.618, un 36,5\%; en cambio diez años después los habitantes en áreas rurales sumaron 93.482 , un $49,7 \%$, en tanto que los residentes en localidades urbanas registraron 94.708, un 50,3\%. Es decir, prácticamente en el último censo se equiparaban la población rural y la urbana, con una leve superioridad de esta última, lo cual sucedía por primera vez en los registros censales de la provincia. Dicho de otro modo, esta equiparidad era el resultado de un descenso de la población de las áreas rurales de un $20 \%$ aproximado con respecto a 1885 , y de un crecimiento de la población en áreas urbanas de un $42 \%$.

Pero el cambio observado en la distribución interna de la población de Concepción no fue el único factor que influyó en la disminución del crédito para los pequeños(as) propietarios(as) agrícolas que, en el caso de nuestro estudio, implicó que la proporción de mujeres campesinas deudoras descendiera de un 32,2\% a solo un $18,2 \%$, como se ve en el cuadro 6. Estimamos que en ello incidió también el menor acceso al crédito que los(as) afectó a medida que la economía regional se modernizaba, dejándose de lado o disminuyendo notoriamente formas tradicionales de pago que, aunque expoliatorias, por lo menos permitían iniciar procesos productivos, como fue el pago de deudas en trigo. En nuestras deudoras campesinas solo encontramos la cancelación en parte en trigo, en algunos mutuos subscritos por María Mella, viuda, y su hijo José Santos Cruz a favor de Fortunato Muñoz; uno de ellos por 1.660 pesos, al subido interés del $1 \frac{1}{2} 2 \%$ mensual y, además, 275 fanegas y nueve almudes de trigo.

Y mientras los campos sufrían la reducción de su población, en las afueras de la ciudad se apiñaban hombres y mujeres, conformando barrios periféricos que extendían el radio urbano. Muchos(as) debieron dedicarse al comercio y a los oficios, otros(as) buscaban simplemente alguna oportunidad para mejorar su subsistencia. Con el tiempo llegaron a ser propietarios(as) de pequeñas propiedades que les permitieron obtener créditos. Así, Luisa Sepúlveda viuda de Concha recibió un mutuo de 300 pesos, al interés del 11/2\% mensual, a cuyo efecto hipotecó un sitio en calle Bulnes de solo ocho varas de frente; Hipólita Figueroa y su esposo se endeudaron con Juan Bautista Melo (prestamista habitual) por 200 pesos, al interés del 11/4\% mensual, con hipoteca de un sitio con lo edificado y plantado, de 13 metros de frente, ubicado en el barrio Agua Negra, que se formó en la periferia norte de la ciudad. Se puede apreciar que aunque se trataba de gente modesta, no por ello se dejaba de cobrarles subidos intereses.

Muchas de las deudoras ubicadas en el área central pertenecían a la elite terrateniente, pero optaban por hipotecar sus propiedades urbanas. Doña Josefa Urrejola viuda de Verdugo, por ejemplo, subscribió un mutuo a favor de doña Manuela Pérez 
Rubio viuda de Soto-Aguilar, por 4.500 pesos, al bajo interés del 8\% anual, hipotecando casa y sitio en esquina en calles Cochrane y Rengo. Las deudoras de otras ciudades de la región tenían su residencia principalmente en Penco y en Tomé; así, José Miguel Galán (prestamista habitual) otorgó un mutuo a Juana María Quiñones, soltera, vecina de Penco, por 2.800 pesos, con interés del 10\% anual, gravando una chacra de seis cuadras y una casa y sitio ubicados en ese puerto. En los préstamos hechos a deudoras residentes en localidades de fuera de la región, citamos a doña Pilar Martínez viuda de Soto, avecindada en Santiago, a quien Juan Migliar, residente en Concepción, facilitó 200 pesos, sin interés, a pagarse en mensualidades de 15 pesos, descontados del canon de una casa que la deudora tenía arrendada al acreedor. Este caso puede ser ilustrativo de un proceso migratorio hacia la capital del país.

\section{MONTOS DE LOS CRÉDITOS}

Las cantidades que las acreedoras otorgaban en préstamo o que las deudoras recibían, eran muy variables. Las informaciones correspondientes al año 1895 indican que en las acreedoras ellas se repartían en una gama que abarcaba desde 100 pesos (v. gr. el que prestó doña Trinidad Jara viuda de Troncoso a Celedonia Escobar, soltera, por un año, al interés del $1 \%$ mensual y con hipoteca de un retazo de sitio en calle Paicaví); hasta la renovación del préstamo de 50.000 pesos hecho por Manuela Murillo viuda de Mahuzier a sus hijos, al que aludimos en páginas anteriores. Ningún acreedor hombre se acercó a esa cantidad, siendo superada solo por créditos bancarios y por el caso particular de una compañía, la firma alemana Münchmeyer y Cía. de Hamburgo que facilitó a su par de Concepción, Mauricio Gleisner y Cía., 20.000 libras esterlinas que al cambio de 17 peniques por peso, representaban más de 280.000 pesos, suma que hemos incluido en la distribución de los montos de los acreedores, como también en la de los deudores (en este caso Gleisner y Cía.), que presentamos en los cuadros 7 y 8.

\section{CUADRO 7 \\ DISTRIBUCIÓN DE LOS MONTOS EN PRÉSTAMO (EN PESOS), SEGÚN CATEGORÍA DE ACREEDORES, 1885 Y 1895}

\begin{tabular}{|c|c|c|c|c|}
\hline \multirow[b]{2}{*}{ Categorías } & \multicolumn{2}{|c|}{1885} & \multicolumn{2}{|c|}{1895} \\
\hline & & $\%$ & & $\%$ \\
\hline Hombres & $362.784,21$ & 29,7 & $987.730,60$ & 23,6 \\
\hline Mujeres & $139.168,37$ & 11,4 & $186.848,86$ & 4,5 \\
\hline Bancos & $618.751,46$ & 50,6 & $2.599 .461,38$ & 62,1 \\
\hline Sociedades & $74.393,00$ & 6,1 & $381.335,38$ & 9,1 \\
\hline Sucesiones & $14.470,50$ & 1,2 & $30.610,00$ & 0,7 \\
\hline Instituciones & $12.209,55$ & 1,0 & $1.315,00$ & 0,0 \\
\hline TOTAL & $1.221 .777,09$ & 100,0 & 4.187.301,22 & 100,0 \\
\hline
\end{tabular}




\section{CUADRO 8 \\ DISTRIBUCIÓN DE LOS MONTOS EN PRÉSTAMO (EN PESOS), SEGÚN CATEGORÍA DE DEUDORES, 1885 Y 1895}

\begin{tabular}{|c|c|c|c|c|}
\hline \multirow[b]{2}{*}{ Categorías } & \multicolumn{2}{|c|}{1885} & \multicolumn{2}{|c|}{1895} \\
\hline & & $\%$ & & $\%$ \\
\hline Hombres & $1.114 .267,16$ & 91,2 & $3.255 .052,78$ & 77,7 \\
\hline Mujeres & $71.061,13$ & 5,8 & $362.898,58$ & 8,7 \\
\hline Sociedades & $15.000,00$ & 1,2 & $492.239,86$ & 11,8 \\
\hline Sucesiones & $21.448,80$ & 1,8 & $22.110,00$ & 0,5 \\
\hline Instituciones & & & $55.000,00$ & 1,3 \\
\hline TOTAL & $1.221 .777,09$ & 100,0 & $4.187 .301,22$ & 100,0 \\
\hline
\end{tabular}

En las deudoras la gama comprende desde los 60 pesos, al interés del 10\% anual, obtenidos por Lucía Bassaletti, soltera, de José María Castro (prestamista habitual), hasta los 24.000 pesos, con interés del 3\% anual, que Francisco Pimentel facilitó a su madre, doña Ignacia Salas viuda de Pimentel, con el propósito expreso de construir una casa en calle O'Higgins. En los deudores hombres los débitos eran más altos; el de mayor cuantía fue el que subscribió Juan Bautista Harriet con el Banco de Chile, por 245.700 pesos, con interés del $6 \%$ anual y a pagarse en seis meses, para lo cual tuvo que hipotecar varias propiedades urbanas.

Las cifras del cuadro 7 son ilustrativas del proceso de modernización de la economía regional, en cuanto a la participación creciente de las entidades bancarias en el mercado del crédito. Hasta entonces habían prevalecido las formas de convivencia tradicionales que se manifestaban, en el tema que tratamos, en el conocimiento recíproco entre acreedores y deudores. En el caso de los bancos, conformados como sociedades anónimas, no interesa quién es el deudor, sino que tenga los suficientes bienes para responder por préstamos que tienden a ser más subidos en su monto que los concedidos por particulares. Ya en el año de inicio del período que consideramos (1885), el monto de los créditos de la banca supera en más de veinte puntos porcentuales a los de los acreedores hombres, representando el $50 \%$ del total de los montos en préstamo, para posteriormente en el año final (1895), empinarse por sobre el 60\% del total de los montos, aproximándose a una triplicación del valor total en números absolutos ${ }^{21}$. Sin embargo, este incremento se aminora si tomamos en cuenta el distinto valor monetario entre un año y otro; como ya hemos señalado en nota 17 , el peso en 1885 representaba un valor de 26

21 En este estudio del crédito, como ya indicamos, consideramos solo los mutuos y las cancelaciones. Hay otros tipos de contratos que incrementan aún más la participación de los bancos en el mercado del crédito, como son las cesiones de créditos y las aperturas de cuentas corrientes; estas últimas en ocasiones son rotuladas bajo el rubro de los mutuos, pero frecuentemente eran inscritas en escrituras diferenciadas. 
peniques, mientras que el cambio en 1895 había bajado a solo 17 peniques por peso. Por lo tanto el valor nominal del total de los préstamos bancarios de 1895 ascendente a 2.599.461,38 pesos, al expresarse al cambio de 1885 representaba solo 1.699.647,82 pesos, con lo que en vez de acercarse a una triplicación, en moneda del mismo valor cambiario ni siquiera alcanzaba a una duplicación. La misma reducción correspondería hacer en las otras categorías de acreedores y de deudores y en la sumatoria total de los montos. Pero más que los números absolutos, para efectos de comparaciones nos interesan los valores porcentuales.

Llama la atención la relativamente escasa participación de las compañías o sociedades comerciales, aunque, como indicamos anteriormente, ocurría a veces que préstamos concedidos por compañías figuraban a nombre del socio principal, omitiéndose el de la respectiva sociedad. En todo caso, ello no es óbice para estimar que, de acuerdo a las informaciones de que disponemos, las sociedades mercantiles regionales no se habían endilgado todavía en el proceso de modernización económica y era poco frecuente que recurrieran al crédito, especialmente al bancario, para su financiamiento. El monto correspondiente a ellas en 1895 se ve abultado por el referido préstamo de una firma alemana a Gleisner y Cía., que a fines del XIX y comienzos del XX era la más moderna empresa domiciliada en Concepción; con dicho préstamo la firma alemana absorbía más del 70\% de las acreencias de las sociedades comerciales, mientras que a la casa Gleisner correspondía el $57 \%$ de las deudas totales de las compañías. Las acreencias y deudas de sucesiones e instituciones mostraban porcentajes insignificantes.

En cuanto a las mujeres acreedoras si bien subió el valor nominal del monto de los créditos que otorgaron, su valor real expresado en pesos de un mismo valor cambiario, experimentó una reducción de 139.168,37 pesos en 1885 a 122.170,40 pesos en 1895. Y en lo que nos interesa destacar para efectos comparativos con otras categorías de acreedores, su peso relativo bajó ostensiblemente de 11,4\% a $4,5 \%$, como efecto de la reducción del mercado crediticio para ellas a la par del proceso de modernización en las gestiones de crédito. En las deudoras, en cambio, el valor nominal de sus débitos subió en forma mucho más acentuada que el incremento nominal correspondiente a las acreedoras, llegando casi a quintuplicarse, aunque en pesos de un mismo valor cambiario el alza fue más moderada: los 362.898,58 pesos correspondientes a las deudas de mujeres en 1895, significaban solo $237.279,84$ pesos en pesos de 26 peniques, suma que también es notoriamente mayor a la de 1885. En otras palabras, al considerarse valores de un mismo poder adquisitivo, las deudas femeninas también se expandieron; en tanto que, proporcionalmente, las deudoras pasaron de casi un 6\% del monto total de las deudas a cerca de un $9 \%$. De manera que al desplazamiento de las mujeres del mercado crediticio en función de acreedoras, no correspondió, por lo menos en la misma proporción, un desplazamiento en la función de deudoras, en la que siguieron teniendo una participación relativamente significativa. 


\section{PARTICIPACIÓN INDIRECTA}

Aparte de su concurrencia al mercado del crédito como acreedoras y deudoras, hubo otras formas de participación que denominamos indirectas. De ellas una de las más frecuentes fue la de servir de fiadoras, respaldando a otros solicitantes de préstamos. Como ejemplos citamos dos casos: doña Carmen Tirapegui viuda de Palacio, afianzó a Mariano Palacio, su cuñado, en un préstamo por $\$ 10.000$, para lo cual doña Carmen hipotecó una hijuela de la hacienda Quilaco, departamento de Mulchén, lindante al norte con el Biobío y "al poniente con terrenos de varios pequeños propietarios del lugar denominado Bajo de Quilaco"22; Camilo Lahaye, comerciante francés, obtuvo un préstamo de 200 pesos, asegurando el cumplimiento del pago con la fianza de su madre Carolina Marolli viuda de Lahaye, quien gravó la parte que le correspondía en una casa y sitio en esquina, calles Lincoyán y Maipú de Concepción. Estas garantías beneficiaban preferentemente a hijos y parientes, aunque a veces también se resguardaba a otras personas.

Otra forma de participación indirecta eran las hipotecas de bienes pertenecientes a las esposas, hechas en mutuos otorgados a sus maridos. Así, Nicolás Rojas, esposo de doña María Luisa Binimelis, contrajo un préstamo por 12.868 pesos, hipotecando la acción y derecho que correspondían a su mujer en un sitio ubicado entre las calles del Comercio y Freire en el área central de la ciudad. En situaciones como esta, no obstante el patriarcado imperante, debía contarse con la aceptación expresa de la mujer: "en este acto compareció doña María Luisa Binimelis, mayor de edad, de este domicilio, a quien conozco y expuso que presta su pleno consentimiento para que su expresado marido haga esta hipoteca en los términos relacionados" 23 . Aunque no se trata de una forma de participación del todo indirecta, ocurría también que mujeres viudas se hacían cargo de los débitos de otras personas, principalmente parientes, cubriendo los montos adeudados. Fue el caso de doña Tránsito Mella viuda de Cruz, que pagó por María Mella, posiblemente su hermana, y por el hijo de esta, José Santos Cruz, deudas que ascendían a más de 7.000 pesos. Asimismo, muchas mujeres viudas tuvieron que responder por deudas dejadas por sus maridos difuntos. Ilustra este tipo de situación, Rafaela Cruz que se vio obligada a completar el pago de 250 pesos, adeudados por el esposo fallecido a Narciso Segundo Silva (prestamista habitual).

Estas formas indirectas y el cubrimiento de deudas no contraídas por ellas, reforzaban la presencia de las mujeres en los mutuos y cancelaciones, incrementando la participación femenina en el mercado crediticio, a pesar de la aparente nimiedad que puedan denotar comparativamente las cifras.

22 ANC, vol. 152, fs. 498-499.

23 Ibidem, vol. 153, fs. 69v-70v. 


\section{CONCLUSIONES}

Quienes se han dedicado a estudios sobre la mujer y sobre género, concuerdan en que con el proceso de modernización las mujeres fueron disminuyendo su presencia en el espacio público, viéndose reforzada su pertenencia a la domesticidad o ámbito privado. Una autora que ha estudiado a las mujeres de los sectores populares, plantea que "la necesidad de disciplinamiento social a través de la constitución de familias obreras, requería de un cambio de actitud de las mujeres populares, ya que las formas tradicionales de ser y estar en la sociedad no se ajustaban a los nuevos modelos de mujer que se necesitaban. Más que una mujer independiente, lo que el modelo necesitaba era una madre, tal cual se reconocía y se aceptaba en las familias de elite. La madre -dueña de casa- esposa se plantea como el modelo a imitar por todas las mujeres". "El desarrollo femenino -agrega- solo podía ser en el espacio de la casa, en tanto se lo concibió como un orden natural que debía ser respetado, de lo contrario se atentaba en contra del equilibrio de las relaciones sociales" 24 . En el caso de las mujeres que estudiamos, pertenecientes a diversos sectores sociales, la disminución de su presencia en el espacio público se denota en su pérdida de importancia en las gestiones crediticias en función de acreedoras, tanto en los valores absoluto y porcentual del número de operaciones realizadas, como en la proporción que les correspondió en el monto total de los créditos concedidos, descenso que fue más acentuado en este último aspecto. Contrariamente a lo ocurrido en la sociedad tradicional colonial, donde llegaron a ser "verdaderos bancos", como fue el caso, según vimos, de las monjas trinitarias, en el tránsito modernizador los bancos fueron reduciendo la participación femenina en el mercado del crédito, aun en mayor proporción que para los varones. Por otra parte, los bancos en sus gestiones financieras dieron pocas oportunidades a las mujeres, siendo muy escasas las que llegaron a abrir cuentas corrientes.

Sin embargo, la pérdida de importancia relativa en su función de acreedoras no fue emparejada en igual forma en su función de deudoras, en la que tanto en el número de operaciones realizadas como en el valor de los montos obtenidos, la participación proporcional de las mujeres deudoras se incrementó.

Hemos intentado aproximarnos a una distribución espacial-social de las deudoras, de la que inferimos que la mayor parte de ellas tenían sus propiedades hipotecadas en barios periféricos que, producto del proceso migratorio rural-urbano, se conformaban en los suburbios de la ciudad, al igual que en otras ciudades del país. La autora antes citada expresa: "Las mujeres populares expulsadas de los campos ante el fracaso del proceso de campesinización -según lo expuesto por Gabriel Salazar- emigran hacia las ciudades y comienzan a instalarse en los bordes de las mismas" 25 . En nuestro estudio las mujeres residentes en los barrios periféricos, se aproximan a cerca de la mitad del total de los débitos de mujeres correspondientes

24 Brito Peña, Alejandra, La construcción de identidades de género en la sociedad popular chilena 1880-1930, Concepción, Ediciones Escaparate, 2005, 119 y 120-121.

25 Ibidem, 51. La referencia es a la obra de Salazar Labradores, peones y proletarios. Formación y crisis de la sociedad popular chilena del siglo XIX, Santiago, Ediciones SUR, 1985. 
a 1895, mientras que decae notoriamente la participación de mujeres deudoras de las áreas rurales, producto también de la migración campo-ciudad, de esa "expulsión" del campo que ellas sufrían. Las deudoras periféricas se endeudan en cantidades bajas, préstamos en torno a 100, 200 y 300 pesos. Aunque, como hemos señalado, las escrituras notariales escasamente especifican el destino de los créditos, podemos suponer que muchas de las habitantes de la periferia se endeudaron para salvar las contingencias del diario vivir. Sustentamos esta suposición en que por entonces llegaba a su fin la etapa de expansión económica regional de la segunda mitad del XIX; asimismo en el alza del costo de la vida que hacía difícil la subsistencia; y en la presencia de numerosos prestamistas, a los que citamos en este texto, siempre dispuestos a facilitar dinero a los necesitados a intereses generalmente elevados. No obstante, más allá de supuestos coherentes, es poco lo que podemos avanzar, lo cual denota la escasez de estudios sobre la historia social de Concepción en el período que consideramos. Creemos que este mismo estudio monográfico es sugerente para abordar temáticas relativas al proceso histórico económico-social de la región.

Otro aspecto que queremos destacar de nuestro trabajo se refiere a la participación económica desde Concepción en el proceso de ocupación de la Araucanía, participación de la que no estuvieron ajenas las mujeres, otorgando créditos a radicados en esa zona y desarrollando allí actividades productivas. Este es un problema interesante de indagar, puesto que de los estudios relativos a dicha ocupación se deduce frecuentemente una desvinculación entre Concepción y la zona fronteriza, sobre todo desde la perspectiva empresarial. Asimismo, resulta insinuante advertir que, en los leves intersticios que quedaban a las mujeres acreedoras, ellas se fueron adaptando a formas más modernas de crédito, tendiendo a cobrar intereses más altos y a aminorar la solidaridad femenina. Por último, un aspecto que mitiga la disminución de la presencia femenina en el mercado del crédito en función de acreedoras, es lo que hemos denominado la "participación indirecta", en la que su concurrencia como fiadoras y las hipotecas de propiedades de esposas hechas por sus maridos, las muestran todavía como un engranaje significativo en los entramados del crédito. 